\title{
Erratum to: Acute airway compromise due to parathyroid tumour apoplexy: an exceptionally rare and potentially life-threatening presentation
}

Aoife Garrahy ${ }^{1 *}$, David Hogan², James Paul O'Neill ${ }^{2}$ and Amar Agha ${ }^{1}$

\section{Erratum}

The original article [1] was updated to correct the order of figure legends. Legend 4 has been moved to Fig. 8, and Legends 5, 6, 7 and 8 have been moved up to Figs. 4, 5, 6 and 7 , respectively. This mistake was carried through by the production team handling this article, and thus was not the fault of the authors.

\section{Author details}

'Department of Endocrinology, Beaumont Hospital, Dublin, Ireland.

${ }^{2}$ Department of Otolaryngology, Head and Neck Surgery, Beaumont Hospital, Dublin, Ireland.

Received: 10 July 2017 Accepted: 10 July 2017

Published online: 14 July 2017

\section{Reference}

1. Garrahy A, Hogan D, O'Neill JP, Agha A. Acute airway compromise due to parathyroid tumour apoplexy: an exceptionally rare and potentially lifethreatening presentation. BMC Endocr Disord. 2017;17:35. doi:10.1186/ s12902-017-0186-2.

* Correspondence: aoife.garrahy@gmail.com

'Department of Endocrinology, Beaumont Hospital, Dublin, Ireland 